\title{
Population growth estimates of a threatened seabird indicate necessity for additional management following invasive predator eradications
}

\author{
J. H. Fischer ${ }^{1}$, G. A. Taylor ${ }^{2}$, R. Cole ${ }^{3}$, I. Debski ${ }^{2}$, D. P. Armstrong ${ }^{4}$ \& H. U. Wittmer ${ }^{1}$ \\ 1 School of Biological Sciences, Victoria University of Wellington, Wellington, New Zealand \\ 2 Aquatic Unit, Department of Conservation, Wellington, New Zealand \\ 3 Murikihu District Office, Department of Conservation, Invercargill, New Zealand \\ 4 Wildlife Ecology Group, Massey University, Palmerston North, New Zealand
}

\section{Keywords}

Bayesian inference; Detection probability; Pelecanoides whenuahouensis; Population size; Population trend; Whenua Hou Diving Petrel; Predator eradications; Invasive species.

\section{Correspondence}

Johannes H. Fischer, School of Biological Sciences, Victoria University of Wellington, PO Box 600, Wellington 6140, New Zealand. Tel: +64-221346676

Email: johannesfischer@live.nl

Editor: Res Altwegg

Associate Editor: Sarah Converse

Received 09 July 2018; accepted 26 April 2019

doi:10.1111/acv.12516

\begin{abstract}
The eradication of invasive predators from islands is a successful technique to safeguard seabird populations, but adequate post-eradication monitoring of native species is often lacking. The Whenua Hou Diving Petrel (Pelecanoides whenuahouensis; WHDP) is a recently-described and 'Critically Endangered' seabird, restricted to Codfish Island (Whenua Hou), New Zealand. Invasive predators, considered the major threat to WHDP, were eradicated on Codfish Island in 2000. However, estimates of WHDP population size and trends remain unknown, hindering assessments of the success of the eradications. We collated intermittent burrow counts ( $n=20$ seasons) conducted between 1978 and 2018. To estimate the population growth rate $(\lambda)$ before and after predator eradications, we used log-linear models in a Bayesian hierarchical framework while retrospectively accounting for differences in detection probabilities among burrow counts, due to differences in effort, marking and timing. The number of WHDP burrows was estimated at 40 (36-46) in 1978 and $100(97-104)$ in 2018. The pre-eradication $\lambda$ was estimated at $1.023(0.959-1.088)$, while the post-eradications $\lambda$ was estimated at 1.017 (1.0061.029). The WHDP population appears to be increasing, yet the rate of increase is low compared to other Procellariiformes following predator eradications. The comparatively low post-eradication $\lambda$, combined with an apparent lack of change between pre- and post-eradication $\lambda$, indicates that additional threats might be limiting WHDP population growth and that further conservation management is required. The continuation of affordable and simple, albeit imperfect, monitoring methods with retrospective corrections facilitated the assessment of invasive predator eradications outcomes and should guide future management decisions. An abstract in Te Reo Māori (the Māori language) can be found in Appendix S1.
\end{abstract}

\section{Introduction}

Close to two-thirds of all recently reported extinctions have occurred on islands, the majority of which have been attributed to predation from invasive species (Tershy et al., 2015; Jones et al., 2016). To counter the detrimental effects of invasive predators, eradication attempts are conducted on many islands. Native species generally respond positively to eradication efforts. Over 200 animal species found on islands have benefited from invasive predator eradications through increases in abundance and/or distribution (Jones et al., 2016; Brooke et al., 2018a). Given these benefits, eradications of invasive predators have become a popular conservation practise with at least 850 island-wide eradications around the globe between 1950 and 2015 (DIISE, 2015).
Invasive predator eradications from islands often play a key role in seabird conservation, as many seabird species breed on islands, or are even endemic to them (Taylor, 2000a 2000b; Spatz et al., 2017; Brooke et al., 2018a; Rodriguez et al., 2019). Seabirds, and notably members of the order Procellariiformes, are one of the most threatened taxonomic groups on the planet (Croxall et al., 2012; Rodriguez et al., 2019). Many Procellariiformes are $K$-strategists (i.e., low fecundity and high longevity). Therefore, these species are highly susceptible to the reduced hatching/fledging success and heightened adult mortality that are typical consequences of invasive predators (Jones et al., 2007; Spatz et al., 2017; Brooke et al., 2018a; Rodriguez et al., 2019). Smaller species $(<1 \mathrm{~kg})$ are especially susceptible to invasive predators (Jones et al., 2007). While Procellariiformes are $K$ - 
strategists, they can respond surprisingly quickly and positively to invasive predator eradications (Jones, 2010; Brooke et al., 2018a). However, despite the clear conservation gains of invasive predator eradications, systematic post-eradication monitoring remains rare (Jones et al., 2016), hindering the evaluation of success and assessments of complementary threats (Spatz et al., 2017; Towns, 2018).

Codfish Island (Whenua Hou), New Zealand, hosts a diverse community of small Procellariiformes and invasive predators were eradicated from the island to restore this seabird community (Middleton, 2007). Specifically, Weka (Gallirallus australis; a predatory bird species native to New Zealand but invasive to Codfish Island; Taylor, 2000a) were eradicated in 1984, followed by brush-tailed possums Trichosurus vulpecula in 1987, and Polynesian rats Rattus exulans in 2000 (dates here represent the year in which the eradications were completed; Brown \& Sherley, 2002; McClelland, 2002; Middleton, 2007). One of the Procellariiform species that breeds on Codfish Island is the "Critically Endangered" Whenua Hou Diving Petrel Pelecanoides whenuahouensis; WHDP hereafter. This species faced major range restrictions and population declines due to the impacts of invasive predators and is now restricted to a single colony on Codfish Island, New Zealand (Taylor, 2000b; Holdaway, Jones \& Athfield, 2003; Fischer et al., 2018a). While invasive predators have been removed from Codfish Island, little is known about past and contemporary population estimates and trends of the WHDP, hindering any assessment of the population responses to the eradication efforts.

To better understand the effects of the eradications of invasive predators on the WHDP, we collated intermittent WHDP burrow counts $(n=20)$ between 1978 and 2018. We then modelled the annual WHDP population growth rates over two biologically relevant time periods: the pre-eradication period (1978-85) and the post-eradication period (2002$18)$. We accounted retrospectively for differences in detection probability among burrow counts due to differences in effort, marking, and timing, using expert elicitation and data on patterns of WHDP attendance at burrows. Finally, we used the existing literature to compare the annual WHDP population growth rate post-eradications with the post-eradication growth rates of other Procellariiformes species on Codfish Island.

\section{Materials and methods}

\section{Study species and study area}

The Whenua Hou Diving Petrel is a small ( 130 g) Procellariiform seabird, which was previously considered conspecific with the South Georgian Diving Petrel (P. georgicus; Fischer et al., 2018a). Following the designation as a new species, the WHDP warrants listing as 'Critically Endangered' on the IUCN Red List (Fischer et al., 2018a). WHDPs were historically widespread through southern New Zealand, but predation by invasive species caused local extinctions throughout their range, including the Chatham Islands, Auckland Islands, Stewart Island and the Otago peninsula (Worthy, 1998; Taylor, 2000b; Holdaway et al., 2003; Wood \& Briden, 2008; Fischer et al., 2017b). Today, the WHDP is restricted to Codfish Island (Whenua Hou, $14 \mathrm{~km}^{2}$, Fig. 1) located circa $3 \mathrm{~km}$ west of Stewart Island (Rakiura), New Zealand. We conducted our study within the only WHDP colony, which is located in the Sealers Bay dunes $\left(-46.766^{\circ} \mathrm{S}, 167.645^{\circ} \mathrm{E}\right.$; Fischer et al., 2017a, 2018b). WHDPs breed in burrows in these dunes from early September to late January, but colony attendance varies with breeding stages (i.e., the species' phenology), which complicates burrow counts.

\section{Burrow counts}

We collated intermittent counts of WHDP burrows based on (1) our own WHDP burrow counts (1991-93, 2002-04, 2008, 2015-18), (2) the scientific literature, and (3) unpublished management reports from the New Zealand Department of Conservation (DOC) (Table 1). All burrow counts were conducted by walking the entirety of the extremely small (approx. $0.018 \mathrm{~km}^{2}$ ) colony back and forth (Taylor \& Cole, 2002; Fischer et al., 2018b). After the first count in 1978 (the year in which the colony was discovered; Imber \& Nilsson, 1980), all detected burrows were marked with stakes during each count (Cox, 1991, R Nilsson pers. comm. 2018). When we found more than one count per season in the literature, we used the earlier count. We only considered counts of occupied WHDP burrows, because not all open burrows in the study area are occupied. We assessed burrow occupancy through stick palisades, sometimes in combination with playback/human mimics (Imber \& Nilsson, 1980; Taylor, 1991; Taylor \& Cole, 2002; Fischer et al., 2018b). As occupancy assessments require $>1$ day, we excluded counts conducted within a single day. Here, we report the calendar year in which the season started.

\section{Modelling population WHDP growth rates}

To estimate the yearly rate of WHDP population growth before and after the invasive predator eradications on

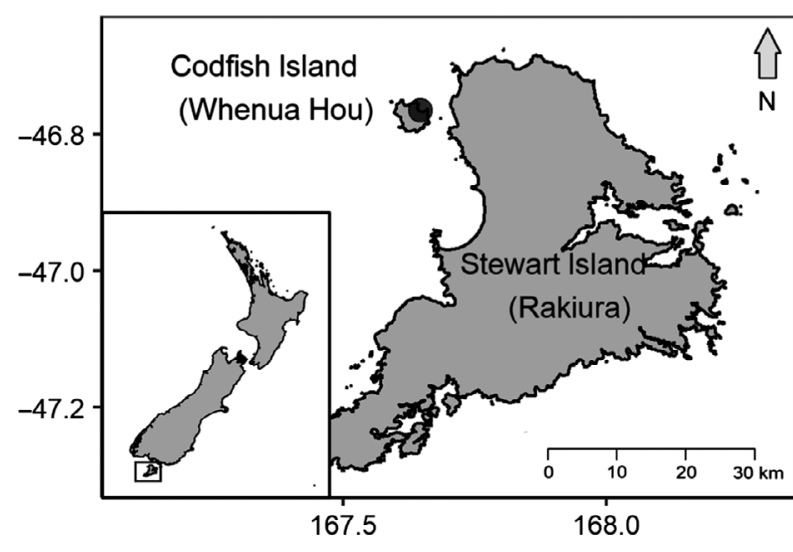

Figure 1 Location of the study site, Sealers Bay dunes, Codfish Island (Whenua Hou), New Zealand, as indicated by the dark-grey circle. 
Table 1. Raw Whenua Hou Diving Petrel burrow counts, number of survey days per count $(d)$, marking of burrows, the timing of the count, proportion of attendance $\left(p_{a, t}\right)$ and corresponding retrospectively corrected estimates $\left(\hat{N}_{t}\right.$ with $95 \%$ credible intervals). $\hat{N}_{t}$ listed here are based on $p_{d, t}$ distributions informed by all 11 experts

\begin{tabular}{|c|c|c|c|c|c|c|c|}
\hline Season & Count & $d$ & Marked & Timing with respect to phenology & $p_{a, t}$ & $\hat{N}_{t}$ & Source \\
\hline 1978 & 35 & 2 & No & Prospecting-incubation & 0.962 & $40(36-46)$ & $\begin{array}{l}\text { Imber \& Nilsson, 1980, R Nilsson pers. } \\
\text { comm. } 2018\end{array}$ \\
\hline 1980 & 32 & 2 & Yes & Incubation & 0.962 & 35 (32-39) & $\begin{array}{l}\text { West \& Imber, 1989, R Nilsson pers. } \\
\text { comm. } 2018\end{array}$ \\
\hline 1981 & 33 & 2 & Yes & Chick-rearing & 0.734 & $45(38-52)$ & $\begin{array}{l}\text { West \& Imber, 1989, R Nilsson pers. } \\
\text { comm. } 2018\end{array}$ \\
\hline 1983 & 38 & 1 & Yes & Chick-rearing & 0.734 & - & $\begin{array}{l}\text { West \& Imber, 1989, A Cox in lit. } \\
2018\end{array}$ \\
\hline 1985 & 41 & 10 & Yes & Prospecting & 0.902 & $45(42-50)$ & West \& Imber (1989) \\
\hline 1990 & 42 & 2 & Yes & Prospecting & 0.902 & $48(44-54)$ & Johnson \& Rance (1990) \\
\hline 1991 & 43 & 3 & Yes & Incubation & 0.962 & $45(43-49)$ & Taylor (1991) \\
\hline 1992 & 41 & 2 & Yes & Incubation & 0.962 & $45(41-49)$ & Buckingham et al. (1995) \\
\hline 1993 & 35 & 6 & Yes & Chick-rearing & 0.734 & $49(42-57)$ & Cole \& Roberts (1994) \\
\hline 1998 & 64 & 1 & Yes & Chick-rearing & 0.734 & - & Imber (1999) \\
\hline 2002 & 75 & 5 & Yes & Incubation & 0.962 & $78(75-81)$ & Cole (2004) \\
\hline 2003 & 54 & 5 & Yes & Incubation-chick-rearing & 0.962 & $57(54-60)$ & Cole (2004) \\
\hline 2004 & 60 & 10 & Yes & Incubation & 0.962 & $63(60-66)$ & Present study \\
\hline 2005 & 72 & 5 & Yes & Incubation & 0.962 & $75(72-78)$ & Trainor (2008) \\
\hline 2006 & 79 & 7 & Yes & Chick-rearing & 0.734 & $99(90-108)$ & Trainor (2008) \\
\hline 2008 & 76 & 4 & Yes & Chick-rearing & 0.734 & $97(88-106)$ & Trainor (2009) \\
\hline 2015 & 74 & 37 & Yes & Incubation-chick-rearing-fledging & 0.962 & $78(74-82)$ & Fischer et al. (2018b) \\
\hline 2016 & 78 & 30 & Yes & Prospecting-incubation-chick-rearing-fledging & 0.962 & $82(78-86)$ & Present study \\
\hline 2017 & 99 & 114 & Yes & Prospecting-incubation-chick-rearing-fledging & 0.962 & $103(99-107)$ & Present study \\
\hline 2018 & 96 & 102 & Yes & Prospecting-incubation-chick-rearing-fledging & 0.962 & $100(97-104)$ & Present study \\
\hline
\end{tabular}

Codfish Island while retrospectively correcting estimates of burrow counts, we fitted log-linear models with a Poisson error term in a Bayesian hierarchical framework. Specifically, we fitted the data to:

$$
\log N_{t}=\alpha+r t+\varepsilon_{t}
$$

in which $N_{t}$ is the number of WHDP burrows at year $t, \alpha$ is $\log N_{O}$ (the number of WHDP burrows at year 0 ), $r$ is the $\log$ $\lambda$ (the finite rate of increase), $t$ is the number of years between 0 and $t$, and $\varepsilon_{t}$ is random annual variation (Caughley, 1977; Caughley \& Sinclair, 1994). We used log-linear models because we assumed the WHDP population to exhibit exponential growth rates. We considered the number of burrows counted each year to be a sampled from a binomial distribution:

$$
N_{t} \sim B\left(N_{t,} p_{t}\right)
$$

in which $p_{t}$ is the probability that a burrow was detected in year $t$. We modelled the expected variation in $p_{t}$ as:

$$
p_{t}=1-\left(1-p_{d, t}\right)^{d} p_{a, t}
$$

in which $p_{d, t}$ is the daily probability that a burrow was detected and identified as occupied by WHDPs, $d$ is the number of survey days in year $\mathrm{t}$, and $p_{a, t}$ is the proportion of the WHDP burrows that were attended to at the time of the breeding season that the count was conducted. We thus retrospectively accounted for imperfect detection in WHDP burrow counts by modelling (1) the search effort each year, (2) the marking of the burrows, and (3) the timing of the count in relation to the species' phenology.

To obtain probability distributions for $p_{d, t}$, we (JHF, DPA and HUW) designed an expert elicitation based on the Delphi method (Linstone \& Turoff, 1975; Kuhnert, Martin \& Griffiths, 2010; Martin et al., 2012). We consulted every living person who had conducted a WHDP burrow count and considered them an expert (excluding JHF, but including GAT, RC, and ID; $n=18$ ). Our approach (Delphi method) consisted of two rounds. In round one, we asked experts independently to provide us with a three-point estimate (their best guess, the minimum and the maximum) of $p_{d}$, provided the colony is (1) marked or (2) unmarked. We thus requested separate values for a marked (i.e., after 1978) and an unmarked colony (i.e., 1978) from the experts, allowing us to adjust $p_{d, t}$ according to whether burrows were marked that year. We assumed that $p_{d}$ was otherwise constant (e.g., no variation due to learning curves of observers, changes in dune vegetation, or other factors that may have varied among years other than marking). In addition, we assumed that all burrows were equally likely to be detected and that misidentification of WHDP burrows was impossible. The experts were aided in their decision in round one by a graph depicting hypothetical detection probabilities $\left(p_{d}=0.1-0.9\right)$ as a function over time (Fig. S1). We then compiled responses $(n=11 ; 61 \%)$ and sent anonymous summary statistics to each respondent, allowing them to adjust their initial response (round two; Linstone \& Turoff, 1975; 
Kuhnert et al., 2010; Martin et al., 2012). Only one response $(6 \%)$ was adjusted in round two (Fig. 2). We obtained beta.PERT distributions (Clark, 1962) for $p_{d, t}$ based on the threepoint estimates from the expert responses in round two.

To obtain a meaningful numerical value for $p_{a, t}$, we monitored WHDP burrows during the entire 2017 and 2018 season ( $n=86$ and 81 , respectively). Specifically, we monitored the daily activity of these burrows using stick palisades (Imber \& Nilsson, 1980; Taylor \& Cole, 2002; Fischer et al., 2018b) to create an attendance curve throughout the season. At the same time, we monitored a subset of burrows in 2017 and 2018 ( $n=29$ and 25, respectively) with a burrowscope (Taupe model, Sextant Technologies, Wellington, New Zealand; Lavers, Hutton \& Bond, 2019) to assess mean dates of key phenology events (i.e., lay, hatch, and fledge dates). We summed the daily burrow attendance per week and allocated these into phenologically relevant stages based on the timing of the count (i.e., prospecting, incubation, chick-rearing or fledging). We then obtained $p_{a, t}$ by averaging the weekly values per phenological category. When counts fell into several phenological stages, we allocated the count into the category with the highest $p_{a, t}$. We assumed that the timing of key phenology events during the 2017 and 2018 season were representative off previous seasons.

We used Equation $1-3$ to estimate $\lambda$ for two biologically relevant time periods: before and after the predator eradications. To estimate the $\lambda$ before the predator eradications, we fitted a model to data between 1978 and 1985. We used the 1978-1985 timeframe because we anticipated a 2-year lag (i.e., the average age at first breeding; Miskelly \& Taylor, 2004, 2007) of the WHDP population to respond to eradication efforts, in the absence of immigration (Codfish Island hosts the only WHDP colony). To estimate $\lambda$ after the predator eradications, we fitted a model to data between 2002 and 2018. In addition, to explore the influence of the expert assessment of $p_{d, t}$ on $\hat{N}_{t}$ and $\hat{\lambda}$, we repeated our analysis three times using distributions for $p_{d, t}$ that were informed by: (1) the average best guess, minimum and maximum from all experts, (2) the values provided by the most pessimistic expert, and (3) the values provided by the most optimistic expert.

We fitted the models using OpenBugs 3.2.3, which uses Markov chain Monte Carlo (MCMC) algorithms to obtain posterior distributions for parameters, allowing all sources of error to be propagated into those distributions (Lunn et al., 2000; Spiegelhalter et al., 2014). We used uninformative priors $(N[0,10])$ for $\alpha$ and $r$. In most cases we pooled three independent MCMC chains with 100000 iterations each after a "burn-in" of 50000 iterations, resulting in posterior distributions based on 150000 iterations. Inspection of the Gelman-Rubin statistic $(\hat{R})$ showed slow convergence of chains for the pre-eradication data based on pessimistic values for $p_{d, t}$, so we increased the number of iterations to 2100000 with a burn in of 50000 , giving satisfactory convergence for all estimates $(\hat{R}<1.05)$ (Paxton et al., 2016). We report posterior distributions of $N_{t}$ and $\lambda$ as means $\pm 95 \%$ credible intervals $(\mathrm{CI})$.

\section{Comparison with other Procellariiformes}

We compared the $\lambda$ of the WHDP population after the eradications of invasive predators with the post-eradication $\lambda$ of other small Procellariform populations breeding on Codfish Island. Specifically, we used existing literature to source $N_{t}$ of both Cook's Petrels (Pterodroma cookii; $\sim 190 \mathrm{~g}$ ) and Mottled Petrels ( $P$. inexpectata; $\sim 315 \mathrm{~g}$ ) on Codfish Island and calculated the $\lambda$ post eradications using Equation 1 (Marchant \& Higgins, 1990). When population estimates were reported as a range only, we used the midpoint as $N_{t}$. As published estimates of both Cook's and Mottled Petrels lacked detail (e.g., details of historic counts were lost and/or counts were only conducted in small parts of the colonies),
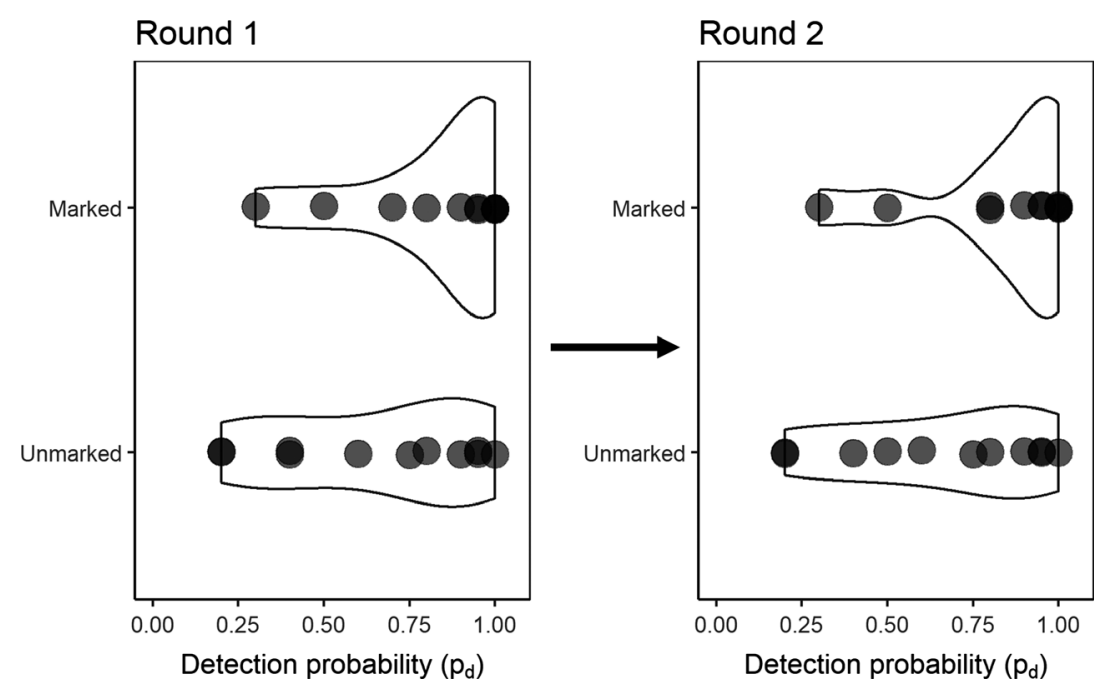

Figure 2 Violin plots illustrating the distribution of best guesses of detection probabilities $\left(p_{d}\right)$ of WHDP burrows in marked/unmarked systems, as provided by experts $(n=11)$ during the two rounds of an expert elicitation following the Delphi method. 
we did not apply Equation 2 and 3 to retrospectively correct these estimates.

\section{Results}

\section{WHDP population growth rates}

A total of 20 raw WHDP burrow counts were collated from 1978 to 2018 (one per breeding season), but two single-day counts were excluded from our analyses (Table 1). The estimates of daily detection probability $\left(p_{d, t}\right)$ obtained by averaging the data from the 11 experts were 0.832 (minimum $=0.761$, maximum $=0.898)$ in a marked colony and $0.662(0.578-0.749)$ in an unmarked colony (Fig. 2). The data from the most pessimistic expert produced an of $p_{d, t}$ of $0.30(0.01-0.60)$ for a marked system and $0.20(0.01-$ $0.40)$ for an unmarked system. The data from the most optimistic expert produced an estimate of $p_{d, t}$ of 0.99 (0.971.00) for a marked system and 0.99 (0.95-1.00) for an unmarked system. The proportion of attended WHDP burrows $\left(p_{a, t}\right)$ per phenological stage was as following: prospecting: September - mid October $p_{a, t}=0.902$; incubation: mid-October - late November $p_{a, t}=0.962$; and chick rearing: late November - mid-January $p_{a, t}=0.734$ (Fig. 3). No counts were conducted solely during fledging.

When using $p_{d, t}$ data informed by the 11 experts, the estimated number of WHDP burrows $\left(\hat{N}_{t}\right)$ varied from 40 (3646) in 1978 to 100 (97-104) in 2018 (Table 1, Fig. 4), the pre-eradication $\lambda(1978-85)$ was estimated at $1.023(0.959$ $1.088)$, and the post-eradication $\lambda(2002-18)$ was estimated at 1.017 (1.006-1.029) (Fig. 5). However, when using the $p_{d, t}$ data informed by the most pessimistic expert, $\hat{N}_{t}$ varied from 59 (48-72) in 1978 to 100 (96-104) in 2018 (Fig. S2), the pre-eradication $\lambda$ was estimated at 0.915 (0.833-0.991), and the post-eradication $\lambda$ was estimated at 1.014 (1.0021.026). When using the $p_{d, t}$ data informed by the most optimistic expert, $\hat{N}_{t}$ varied from 36 (35-39) WHDP burrows in
1978 to 100 (97-104) WHDP burrows in 2018 (Fig. S3), the pre-eradication $\lambda$ was estimated at $1.038(0.975-1.103)$, and post-eradication $\lambda$ was estimated at 1.017 (1.006-1.029).

\section{Comparison with other Procellariformes}

The Cook's Petrel population on Codfish Island grew from 100 burrows in 1980 to approximately 5000 (3500-7000) burrows in 2007. The $\lambda$ for this period for Cook's Petrel was 1.156 (Fig. 5). The Mottled Petrel population on Codfish Island grew from $10000-50000$ burrows in 1980 to $300000-400000$ burrows in 1996. The $\lambda$ for this time period for Mottled Petrel was 1.155 .

\section{Discussion}

We presented WHDP burrow estimates for the last four decades, which ranged from $\hat{N}_{t}=40(36-46)$ burrows in 1978 to $\hat{N}_{t}=100$ (97-104) burrows in 2018 (using $p_{d, t}$ data averaged from the 11 experts). Under the assumption that every burrow was occupied by two adults, these estimates would equate to 80 (72-92) adults in 1978 and 200 (194-208) adults in 2018. These estimates highlighted that the WHDP population slowly increased over the last 40 years but remains very low. In addition, we also presented the first estimates of the annual population growth rate of the WHDP. The pre-eradication $\lambda(1978-85)$ was 1.023 , while the post-eradication $\lambda(2002-18)$ was 1.017 using $p_{d, t}$ data informed all 11 experts. Both estimates of $N_{t}$ and $\lambda$ (based on $p_{d, t}$ data informed all 11 experts) indicated that the WHDP population was slowly increasing before invasive predator eradications and still is slowly increasing afterwards.

Comparing raw burrow counts with our estimates derived from retrospective corrections highlighted the importance of accounting for differences in detection probability among burrow counts due to differences in effort and timing.

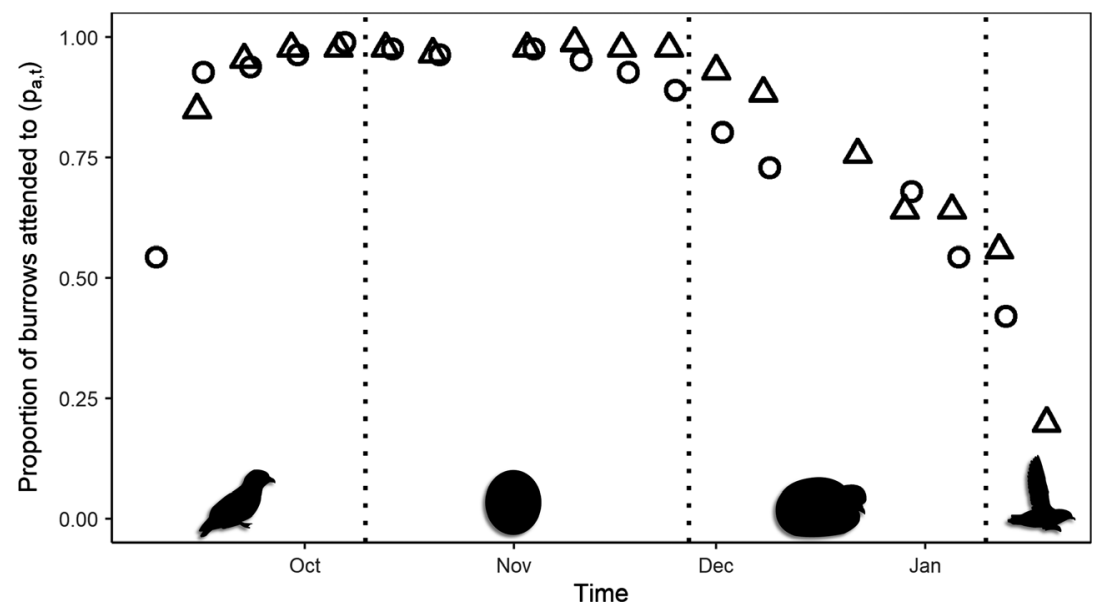

Figure 3 The proportion of Whenua Hou Diving Petrel burrows that were attended to $\left(p_{a, t}\right)$ in relation to key phenology events (prospecting, incubation, chick-rearing or fledging) during the 2017 (triangles; $n=86$ ) and the 2018 (circles, $n=81$ ) breeding seasons. Dotted lines represent mean lay (09 October), hatch (26 November) and fledge dates (11 January). 


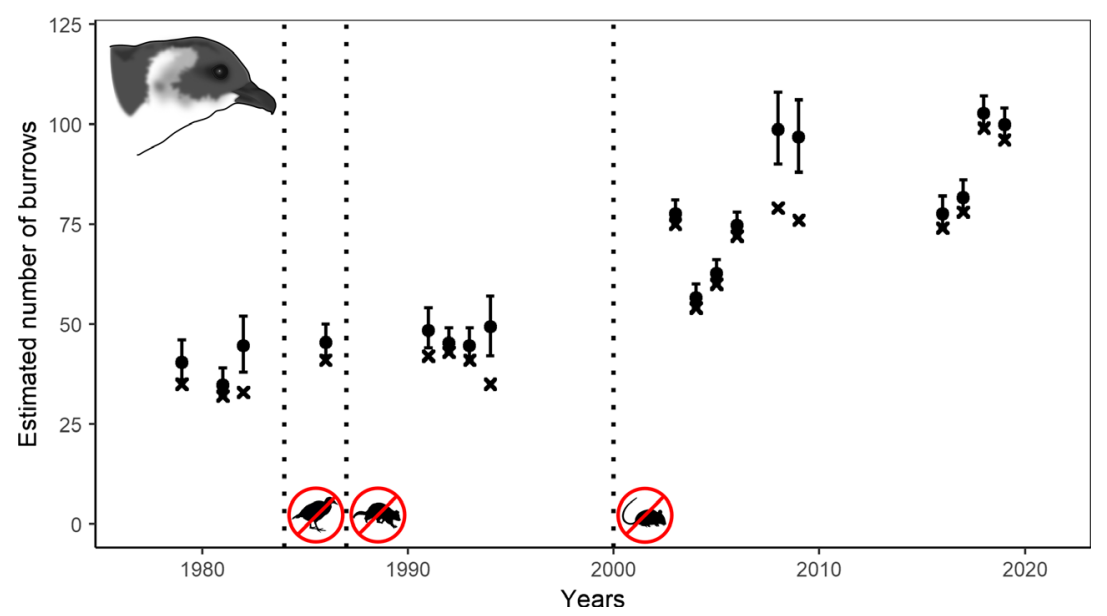

Figure 4 Raw Whenua Hou Diving Petrel burrow counts (crosses) and retrospectively corrected estimates $\left(\hat{N}_{t}\right.$; filled circles with $95 \%$ credible intervals), based on $p_{d, t}$ distributions informed by all 11 experts, in relation to invasive predator eradications (dotted lines).

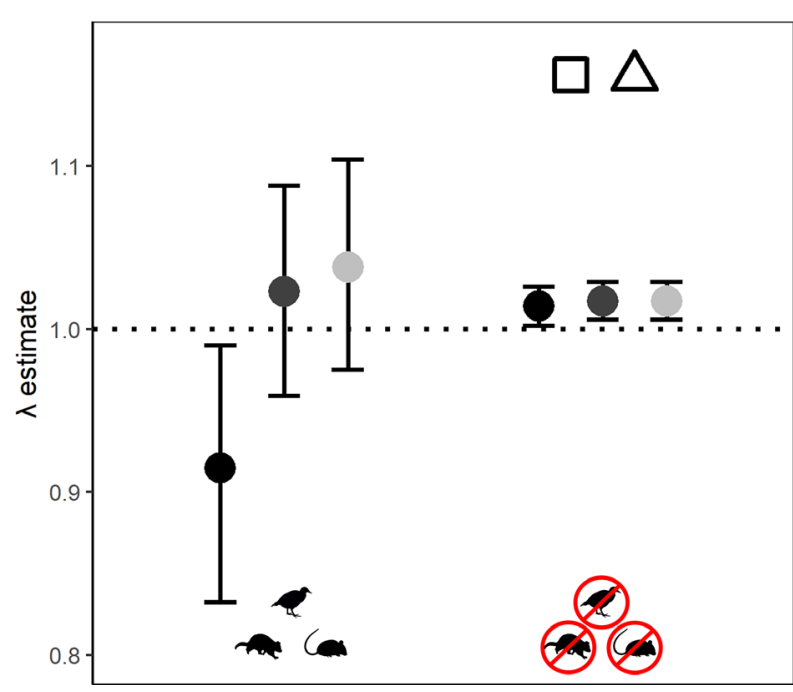

Figure 5 Estimates of yearly rates of WHDP population growth $(\lambda)$, before and after eradications of invasive predators (filled circles with $95 \%$ credible intervals; orange $=$ based on $p_{d, t}$ distributions informed by most pessimistic expert, black $=$ based on $p_{d, t}$ distributions informed by all 11 experts, and green $=$ based on $p_{d, t}$ distributions informed by most optimistic expert), in comparison with estimates of Cook's Petrel (hollow triangle) and Mottled Petrel (hollow square) $\lambda$ post eradications. Cook's and Mottled Petrel population $\lambda$ are based on (Robertson \& Bell, 1984; Taylor, 2000a; Imber, West \& Cooper, 2003; Rayner, Parker \& Imber, 2008).

Seasons in which counts were conducted during chick-rearing (i.e., counts with the lowest $p_{a, t}$ ) had the greatest difference between the raw burrow counts and $\hat{N}_{t}$. Furthermore, burrow counts with a low number of survey days (d) resulted in $\hat{N}_{t}$ with larger credible intervals, highlighting the importance of spending adequate time in the field
(MacKenzie et al., 2002, 2003). The increased confidence in estimates caused by increased survey effort is also apparent in the $\lambda$ estimates. The time spent in the WHDP colony after the eradications is considerably higher than before the eradications. Consequently, the $\lambda$ estimates post-eradications do not vary, even with different distributions for $p_{d, t}$. In contrast, the pre-eradication $\lambda$ vary substantially under different distributions for $p_{d, t}$. Most noticeably, when using the $p_{d, t}$ data informed the most pessimistic expert, the pre-eradication $\lambda$ indicated a decreasing WHDP population $(\lambda=0.915)$. However, when compared to detection probabilities of burrows of other Procellariiform species that breed in more vegetated habitats than the WHDP (Barbraud et al., 2009; Defos du Rau et al., 2015), the $p_{d, t}$ distributions informed by the most pessimistic expert appeared to be underestimates. As such, the $p_{d, t}$ distributions based on values provided by all eleven experts seemed a more realistic estimate.

The post-eradication $\lambda$ of the WHDP population contrasted with the $\lambda$ of other small Procellariiformes post eradications. For example, the population doubling time $\left(t_{d}\right)$ for the Cook's $\left(t_{d}=4.49\right.$ years $)$ and Mottled Petrels $\left(t_{d}=4.52\right.$ years $)$ on Codfish Island was 9.2 and 9.1 times shorter, respectively, than the population doubling time of the WHDP $\left(t_{d}=41.18\right.$ years) (Caughley \& Sinclair, 1994). The average population growth rate of 24 Procellariiform populations (17 small $[<1 \mathrm{~kg}]$ species) after invasive predator eradications was $\lambda=1.079$ (populations established after the eradications were excluded; Brooke et al., 2018a). Therefore, the average population doubling time of small Procellariiformes population was $t_{d}=8.86$ years, which is 4.65 times shorter than the $t_{d}$ of the WHDP. Brooke et al. (2018a) highlighted that many seabird species respond rapidly to eradications, potentially due to a pool of immature birds. Our intermittent time series did not cover the two years after the eradications (2000-2002; the timeframe in which WHDP immatures would have responded; Miskelly \& Taylor, 2004, 2007), preventing assessments of WHDP 
responses immediately after the eradications. Regardless of this shortcoming in our study, the population responses of most other Procellariiformes post-eradication efforts were considerably higher than the population response of the WHDP.

The lack of change between the pre- and post-eradication $\lambda$ and the low post-eradication $\lambda$ indicated that after the invasive predator eradications other factors remained that limit the WHDP population growth and that additional management is required. Various factors could be limiting WHDP population recovery. The distinct preference of the WHDP to only breed in fragile foredunes suggests that the species is extremely vulnerable to storms and storm surges (Fischer et al., 2018b). For example, a storm in October 2003 eroded the foredune in which the WHDP breeds, caused nest failures, and increased adult mortality (Cole, 2004). A translocation could reduce the vulnerability of the WHDP to these stochastic events (Miskelly \& Taylor, 2004; Miskelly et al., 2009). Density dependence could be another explanation to the limited population growth of the WHDP. However, diving petrel colonies have been shown to reach much higher densities (e.g., 6 burrows $/ \mathrm{m}^{2}$; Taylor, 2000b) than the current density of the WHDP colony $\left(0.006\right.$ burrows $\left./ \mathrm{m}^{2}\right)$. Negative interspecific interactions between the WHDP and the Common Diving Petrels (Fischer et al., 2017a) could also be limiting population growth. While the (meta)population of the Common Diving Petrel within the WHDP colony appeared small (Taylor \& Cole, 2002; Fischer et al., 2018b), measures reducing interspecific interactions (e.g., burrow flaps; Gummer et al., 2015) could be considered. Furthermore, no pelagic threats to the WHDP have been assessed to date. Therefore, its pelagic distribution and associated threats, including deck strikes, accidental bycatch in commercial fisheries or environmental variability, should be investigated (Taylor, 2000a, 2000b; Black, 2005; Pardo et al., 2017).

While we were unable to identify the factor(s) limiting WHDP population growth, our study illustrated the value of inexpensive and simple, albeit imperfect, field data in combination with retrospective corrections to evaluate the success invasive predator eradications. Eradications of invasive predators from islands have been extremely successful in restoring seabird populations (Jones et al., 2016; Spatz et al., 2017; Brooke et al., 2018a) and the eradications on Codfish Island clearly were beneficial for the Cook's and Mottled Petrel populations (Fig. 5). Yet, eradications of invasive predators do not exclude the need for follow-up conservation measures (e.g., a translocation for WHDPs). Brooke et al. (2018a) found that seven seabird populations did not respond to eradication efforts (e.g., Gould's Petrel Pterodroma gouldii) and at least 23 seabird populations responded negatively $(\lambda<1)$, suggesting that the limited population response of the WHDP was not an isolated case. Due to the prevalent assumption that native species will be secured following island eradications, monitoring of native fauna post-eradication is rare and thus cases requiring additional management are unlikely to be recognized (Jones et al., 2016; Brooke et al., 2018a,2018b; Towns, 2018). The "unavailability of economical ways to measure change" was listed as another impediment to post-eradication monitoring (Towns, 2018). In addition, the allocation of sparse funds towards (1) monitoring the responses of native species following eradications or (2) future eradications continues to be debated (Brooke et al., 2018b). This conundrum is aggravated by the longevity of seabirds (among other long-lived species), as the posteradication monitoring of these species would ideally span decades, further elevating monitoring costs (Brooke et al., 2018a,2018b; Towns, 2018). Both Towns (2018) and Brooke et al. (2018b) highlight the need for simple, inexpensive monitoring methods that have the potential to assess eradication outcomes over extended time periods. Although detailed (and thus often expensive) monitoring schemes following invasive predator eradications (or even in general) are largely missing (Paleczny et al., 2015; Towns, 2018), basic, but imperfect data (such as burrow counts) do often exist (e.g., Taylor, 2000a,2000b). Our results demonstrate that relatively inexpensive monitoring approaches (e.g., burrow-counts), combined with retrospective corrections, can be informative and allow for evaluations of management success across extended time periods, even when monitoring has been intermittent. We thus advocate the use of imperfectly collected historic data and recommend the continuation of similar simple and inexpensive monitoring methods post-eradications to inform outcomes of invasive predator eradications and consequently, future conservation management.

\section{Acknowledgements}

We are very grateful to the Ngāi Tahu for granting visits to Codfish Island. We are greatly indebted to dozens of volunteers over the past four decades for their assistance in the field. We thank William Brockelsby for his assistance in retrieving unpublished reports. We are also grateful to all experts who participated in the expert elicitation. Additionally, we thank Janne de Hoop, David Young and Victor Anton for providing the electronic artwork. Finally, we thank Victor Anton, Sarah Converse, Michelle McLellan, Alice Rogers, and two anonymous reviewers for commenting on previous versions of this manuscript.

\section{Conflict of interest}

The authors have no conflict of interest to declare.

\section{Funding information}

This work was supported by the New Zealand Department of Conservation, the National Geographic Society [WW249C-17], the Ornithological Society of New Zealand [Bird NZ Research Fund 2015, 2017], the Encounter Foundation, Forest and Bird [JS Watson Trust 2017], a public Experiment.com crowdfunder [https://doi.org/10.18258/7331], the Centre for Biodiversity and Restoration Ecology [Student Award 2015, 2017], the Coastal Restoration Trust of New Zealand [Postgraduate Student Study Award 2016], The Royal Society of New Zealand [Hutton Fund 2017], and the Australasian Seabird Group [Student Grant 2016]. 


\section{Ethics statement}

All field protocols were approved by the internal Animal Ethics Committee of DOC and/or the Animal Ethics Committee of Victoria University of Wellington (VUW AEC 22252 and 23283).

\section{References}

Barbraud, C., Delord, K., Marteau, C. \& Weimerskirch, H. (2009). Estimates of population size of white-chinned petrels and grey petrels at Kerguelen Islands and sensitivity to fisheries. Anim. Conserv. 12, 258-265.

Black, A. (2005). Light induced seabird mortality on vessels operating in the Southern Ocean: incidents and mitigation measures. Antarct. Sci. 17, 67-68.

Brooke, M.L., Bonnaud, E., Dilley, B.J., Flint, E.J., Holmes, N.D., Jones, H.P., Provost, P., Rocamora, G., Ryan, P.G., Surman, C. \& Buxton, R.T. (2018a). Seabird population changes following mammal eradications on islands. Anim. Conserv. 21, 3-12.

Brooke, M.L., Bonnaud, E., Dilley, B.J., Flint, E.J., Holmes, N.D., Jones, H.P., Provost, P., Rocamora, G., Ryan, P.G., Surman, C. \& Buxton, R.T. (2018b). Enhancing the value of future island eradications needs improved understanding of past outcomes. Anim. Conserv. 21, 19-20.

Brown, K.P. \& Sherley, G.H. (2002). The eradication of possums from Kapiti Island, New Zealand. Turning the Tide 27, 46-52.

Buckingham, R., Torr, S., Hamish, L. \& Cole, R. (1995). Management of Codfish Island: October 1992 - June 1993. Invercargill: Department of Conservation.

Caughley, G. (1977). Analysis of vertebrate populations. Toronto: John Wiley and Sons.

Caughley, G. \& Sinclair, A.R.E. (1994). Wildlife ecology and management. Oxford: Blackwell Science.

Clark, C.E. (1962). Letter to the editor - the PERT model for the distribution of an activity time. Oper. Res. 10, 405406.

Cole, R. (2004). Summary of South Georgian Diving Petrel field observations for 2003/04, Codfish Island/Whenua Hou. Invercargill: Department of Conservation.

Cole, R. \& Roberts, A. (1994). Management of Codfish Island: July 1993 - June 1994. Invercargill: Department of Conservation.

Cox, A. (1991). Scientific and management marking Codfish Island. Invercargill: Department of Conservation.

Croxall, J.P., Butchart, S.H.M., Lascelles, B., Stattersfield, A.J., Sullivan, B., Symes, A. \& Taylor, P. (2012). Seabird conservation status, threats and priority actions: a global assessment. Bird Conserv. Int. 22, 1-34.

Defos du Rau, P., Bourgeois, K., Thévenet, M., Ruffino, L., Dromzée, S., Ouni, R., Abiadh, A., Estève, R., Durand, J.-P., Anselme, L., Faggio, G., Yahya, J.M., Rguibi, H., Renda, M., Miladi, B., Hamrouni, H., Alilech, S., Nefla, A., Jaouadi, W.,
Agrebi, S. \& Renou, S. (2015). Reassessment of the size of the Scopoli's Shearwater population at its main breeding site resulted in a tenfold increase: implications for the species conservation. J. Ornithol. 156, 877-892.

DIISE. (2015). The Database of Island Invasive Species Eradications, developed by Island Conservation, Coastal Conservation Action Laboratory UCSC, IUCN SSC Invasive Species Specialist Group, University of Auckland and Landcare Research New Zealand. Available at http://diise. islandconservation.org. (accessed 14 March 2018).

Fischer, J.H., Debski, I., Taylor, G.A. \& Wittmer, H.U. (2017a). Assessing the suitability of non-invasive methods to monitor interspecific interactions and breeding biology of the South Georgian diving petrel (Pelecanoides georgicus). Notornis 64, 13-20.

Fischer, J.H., Hjorsvarsdottir, F.O., Hiscock, J.A., Debski, I., Taylor, G.A. \& Wittmer, H.U. (2017b). Confirmation of the extinction of South Georgian diving petrels (Pelecanoides georgicus) on Enderby Island. Notornis 64, 48-51.

Fischer, J.H., Debski, I., Miskelly, C.M., Tennyson, A.J.D., Fromant, A., Tessler, J., Hiscock, J.A., Cole, R., Bost, C.A., Taylor, G.A. \& Wittmer, H.U. (2018a). Analyses of phenotypic differentiations between South Georgian Diving Petrel (Pelecanoides georgicus) populations reveal an undescribed and highly-endangered species from New Zealand. PLOS ONE 13, e0197766.

Fischer, J.H., Debski, I., Taylor, G.A. \& Wittmer, H.U. (2018b). Nest-site selection of South Georgia Diving-petrels on Codfish Island (Whenua Hou), New Zealand: implications for conservation management. Bird Conserv. Int. 28, 216-227.

Gummer, H., Taylor, G., Wilson, K.J. \& Rayner, M.J. (2015). Recovery of the endangered Chatham Petrel (Pterodroma axillaris): A review of conservation management techniques from 1990 to 2010. Glob. Ecol. Conserv. 3, 31-330.

Holdaway, R.N., Jones, M.D. \& Athfield, N.R.B. (2003). Establishment and extinction of a population of South Georgian diving petrel (Pelecanoides georgicus) at Mason Bay, Steward Island, New Zealand, during the late Holocene. J. Roy. Soc. New Zeal. 33, 601-622.

Imber, M.J. (1999). Report on Codfish Island trip to set up Cook's petrel long-term monitoring grids for Southland Conservancy. Invercargill: Department of Conservation.

Imber, M.J. \& Nilsson, R.J. (1980). South Georgian diving petrels (Pelecanoides georgicus) breeding on Codfish Island. Notornis 27, 325-330.

Imber, M.J., West, J.A. \& Cooper, W.J. (2003). Cook's petrel (Pterodroma cookii): historic distribution, breeding biology, and effects of predators. Notornis 50, 221-230.

Johnson, P. \& Rance, B. (1990). Codfish Island Trip Report. Invercargill: Department of Conservation.

Jones, H.P. (2010). Seabirds take mere decades to recover following rat eradications. Ecol. App. 20, 2075-2080.

Jones, H.P., Tershy, B.R., Zavaleta, E.S., Croll, D.A., Keitt, B.S., Finkelstein, M.E. \& Howald, G.R. (2007). Severity of 
the effects of invasive rats on seabirds: A global review. Conserv. Biol. 22, 16-26.

Jones, H.P., Holmes, N.D., Butchart, S.H.M., Tershy, B.R., Kappes, P.J., Corkery, I., Aguirre-Munoz, A., Armstrong, D.P., Bonnaud, E., Burbidge, A.A., Campbell, K., Courchamp, F., Cowan, P.E., Cuthbert, R.J., Ebbert, S., Genovesi, P., Howald, G.R., Keitt, B.S., Kress, S.W., Miskelly, C.M., Oppel, S., Poncet, S., Rauzon, M.J., Rocamora, G., Russel, J.C., Samaniego-Herrera, A., Seddon, P.J., Spatz, D.R., Towns, D.R. \& Croll, D.A. (2016). Invasive mammal eradication on island results in substantial conservation gains. Proc. Natl Acad. Sci. USA 113, 4033-4038.

Kuhnert, P.M., Martin, T.G. \& Griffiths, S.P. (2010). A guide to eliciting and using expert knowledge in Bayesian ecological models. Ecol. Lett. 13, 900-914.

Lavers, J.L., Hutton, I. \& Bond, A.L. (2019). Changes in technology and imperfect detection of nest contents impedes reliable estimates of population trends in burrowing seabirds. Glob. Ecol. Conserv. 17, e00579.

Linstone, H. A. and Turoff, M. (1975).The Delphi Method. Reading: Addison-Wessley.

Lunn, D.J., Thomas, A., Best, N. \& Spiegelhalter, D. (2000). WinBUGS - a Bayesian modelling framework: concepts, structure, and extensibility. Stat. Comput. 10, 325-337.

MacKenzie, D.I., Nichols, J.D., Lachman, G.B., Droege, S., Royle, J.A. \& Langtimm, C.A. (2002). Estimating site occupancy rates when detection probabilities are less than one. Ecology 83, 2248-2255.

MacKenzie, D.I., Nichols, J.D., Hines, J.E., Knutson, M.G. \& Franklin, A.B. (2003). Estimating site occupancy, colonization, and local extinction probabilities when a species is detected imperfectly. Ecology 84, 2200-2207.

Marchant, S. and Higgins, P.J. (1990). Handbook of Australian, New Zealand \& Antarctic birds. Volume 1, ratites to ducks, part A, ratites to petrels. Melbourne: Oxford University Press.

Martin, T.G., Burgman, M.A., Fidler, F., Kuhnert, P.M., LowChoy, S., McBride, M. \& Mengersen, K. (2012). Eliciting expert knowledge in conservation science. Conserv. Biol. 26, 29-38.

McClelland, P.J. (2002). Eradication of Pacific rats (Rattus exulans) from Whenua Hou Nature Reserve (Codfish Island), Putauhinu and Rarotoka Islands, New Zealand. Turning the Tide 27, 173-181.

Middleton, A. (2007). Two hundred years on Codfish Island (Whenuahou). Invercargill: Department of Conservation.

Miskelly, C.M. \& Taylor, G.A. (2004). Establishment of a colony of Common Diving Petrels (Pelecanoides urinatrix) by chick transfers and acoustic attraction. Ети 104, 205211.

Miskelly, C.M. \& Taylor, G.A. (2007). Common Diving Petrel (Pelecanoides urinatrix) breeding at 1 year old. Notornis 54, 239-240.

Miskelly, C.M., Taylor, G.A., Gummer, H. \& Williams, R. (2009). Translocations of eight species of burrow-nesting seabirds (genera Pterodroma, Pelecanoides, Pachyptila and Puffinus: Family Procellariidae). Biol. Conserv. 142, 19651980.

Paleczny, M., Hammill, E., Karpouzi, V. \& Pauly, D. (2015). Population Trend of the World's Monitored Seabirds, 19502010. PLOS ONE 10, e0129342.

Pardo, D., Forcada, J., Wood, A.G., Tuck, G.N., Ireland, L., Pradel, R., Croxall, J.P. \& Phillips, R.A. (2017). Additive effects of climate and fisheries drive ongoing declines in multiple albatross species. Proc. Natl Acad. Sci. USA 114, E10829-E10837.

Paxton, E.H., Camp, R.J., Gorresen, P.M., Crampton, L.H., Leonard, D.L. \& VanderWerf, E.A. (2016). Collapsing avian community on a Hawaiian Island. Sci. $A d v .2$, e1600029.

Rayner, M.J., Parker, K.A. \& Imber, M.J. (2008). Population census of Cook's petrel Pterodroma cookii breeding on Codfish Island (New Zealand) and the global conservation status of the species. Bird Conser. Int. 18, 211-218.

Robertson, C.J.R. and Bell, B.D. (1984). Seabird status and conservation in the New Zealand region. In Status and conservation of the world's seabirds: 573-586. Croxall, J.P., Evans, P.G.H. and Schreiber, R.W.(Eds.). Cambridge: ICBP Technical publication 2 .

Rodriguez, A., Arcos, J.M., Bretagnolle, V., Dias, M.P., Holmes, N.D., Louzao, M., Provencher, J., Raine, A.F., Ramirez, F., Rodriguez, B., Ronconi, R.A., Taylor, R.S., Bonnaud, E., Borrelle, S.B., Cortes, V., Descamps, S., Friesen, V.L., Genovart, M., Hedd, A., Hodum, P., Humphries, G.R.W., Le Corre, M., Lebarbenchon, C., Martin, R., Melvin, E.F., Montevecchi, W.A., Pinet, P., Pollet, I.L., Ramos, R., Russell, J.C., Ryan, P.G., Sanz-Aguilar, A., Spatz, D.R., Travers, M., Votier, S.C., Wanless, R.M., Woehler, E. \& Chiaradia, A. (2019). Future directions in conservation research on petrels and shearwaters. Front. Mar. Sci. 6, 94.

Spatz, D.R., Holmes, N.D., Reguero, B.G., Butchart, S.H.M., Tershy, B.R. \& Croll, D.A. (2017). Managing invasive mammals to conserve globally threatened seabirds in a changing climate. Conserv. Lett. 10, 736-747.

Spiegelhalter, D., Thomas, A., Best, N. \& Lunn, D. (2014). OpenBUGS User Manual, Version 3.2.3. Cambridge: MRC Biostatistics Unit.

Taylor, G. (1991). Report on a visit to Codfish Island 1-7 November 1991. Wellington: Department of Conservation.

Taylor, G.A. (2000a). Action Plan for Seabird Conservation in New Zealand. Part A: Threatened seabirds. Wellington: Department of Conservation.

Taylor, G.A. (2000b). Action Plan for Seabird Conservation in New Zealand. Part B: Non-threatened seabirds.

Wellington: Department of Conservation.

Taylor, G. \& Cole, R. (2002). South Georgian Diving Petrel (Pelecanoides georgicus) survey, Codfish Island/Whenua Hou. Wellington: Department of Conservation.

Tershy, B.R., Shen, K.-W., Newton, K.M., Holmes, N.D. \& Croll, D.A. (2015). The importance of islands for the 
protection of biological and linguistic diversity. Bioscience 65, 592-597.

Towns, D.R. (2018). Understanding seabird responses to invasive mammal eradications from islands needs systematic monitoring. Anim. Conserv. 21, 15-16.

Trainor, S. (2008). Codfish Island South Georgian Diving Petrel: a summary of field observations 2004-2007 and recommendations for future management. Invercargill: Department of Conservation.

Trainor, S. (2009). South Georgian Diving Petrel: a summary of field observations 2007-2009 on Codfish Island. Invercargill: Department of Conservation.

West, J. \& Imber, M.J. (1989). Surveys of South Georgian diving petrels (Pelecanoides georgicus) on Codfish Island. Notornis 36, 157-158.

Wood, J.R. \& Briden, S. (2008). South Georgian diving petrel (Pelecanoides georgicus) bones from a Maori midden in Otago Peninsula, New Zealand. Notornis 55, 46-47.

Worthy, T.H. (1998). Fossils indicate Pelecanoides georgicus had large colonies at Mason Bay, Stewart Island, New Zealand. Notornis 45, 229-246.

\section{Supporting information}

Additional supporting information may be found online in the Supporting Information section at the end of the article.

Figure S1. Hypothetical detection probabilities $\left(p_{d}\right)$ with values varying between 0.1 and 0.9 as a function of time to aid experts in their decision-making during an expert elicitation.

Figure S2. Raw Whenua Hou Diving Petrel burrow counts (crosses) and retrospectively corrected estimates (; filled circles with $95 \%$ credible intervals), based on $p_{d, t}$ distributions informed by the most pessimistic expert, in relation to invasive predator eradications (dotted lines).

Figure S3. Raw Whenua Hou Diving Petrel burrow counts (crosses) and retrospectively corrected estimates (; filled circles with $95 \%$ credible intervals), based on $p_{d, t}$ distributions informed by the most optimistic expert, in relation to invasive predator eradications (dotted lines).

Appendix S1. Abstract in Te Reo Māori/the Māori language. 


\section{Graphical Abstract}

The contents of this page will be used as part of the graphical abstract of html only. It will not be published as part of main article.

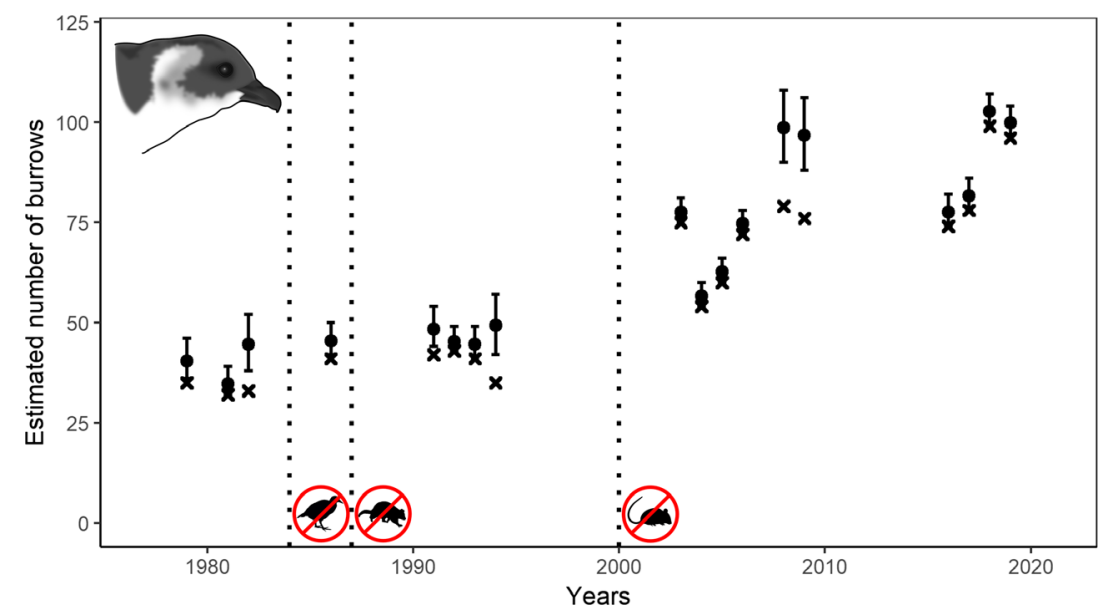

The eradication of invasive predators from islands is a successful technique to safeguard seabird populations, but adequate post-eradication monitoring of native species is often lacking. To estimate the population growth rate $(\lambda)$ of Whenua Hou diving petrels (WHDP) before and after predator eradications, we used log-linear models in a Bayesian hierarchical framework while retrospectively accounting for differences in detection probabilities among burrow counts, due to differences in effort, marking and timing. Results showed a comparatively low post-eradication $\lambda$ and an apparent lack of change between pre- and post-eradication $\lambda$, indicating that additional threats might be limiting WHDP population growth and that further conservation management is required. 